\title{
Study Personnel Primary Indicator
}

National Cancer Institute

\section{Source}

National Cancer Institute. Study Personnel Primary Indicator. NCI Thesaurus. Code C94102.

Specifies whether this is the main or principal study personnel. 